\title{
Campus Food Movements and Community Service-Learning: Mobilizing Partnerships through the Good Food Challenge in Canada
}

\author{
Charles Z. Levkoe, Simon Erlich, Sarah Archibald
}

\begin{abstract}
This paper addresses the growing collaborations among students, faculty and community-practitioners attempting to build healthy, equitable and sustainable food systems within post-secondary institutions and the ensuing implications for food movements. Specifically, we investigate the role of Community Service-Learning (CSL) in fostering food systems change through a case study of Planning for Change: Community Development in Action, a graduate CSL course at the University of Toronto and a partnership with Meal Exchange, a national non-profit organization, to develop the Good Food Challenge on college and university campuses across Canada. Using CSL to support social movements is not uncommon; however, there has been little application of these pedagogical approaches within the field of food systems studies, especially in the area of campus food movements that engage diverse groups in mutually beneficial and transformative projects. Our description of the case study is organized into three categories that focus on key sites of theory, practice and reflection: classroom spaces, community spaces and spaces of engagement. Through reflection on these spaces, we demonstrate the potential of CSL to contribute to a more robust sustainable food movement through vibrant academic and community partnerships. Together, these spaces demonstrate how campus-based collaborations can be strategic levers in shifting towards more healthy, sustainable and equitable food systems.
\end{abstract}

KEYWords community service-learning; critical praxis; food systems; spaces of engagement; social movements

The corporate, industrial food system has come under immense scrutiny because of the social, economic and ecological problems it contributes to across the globe (Weis, 2007; Akram-Lodhi, 2013). Now, more than ever, responses are needed that can address pressing concerns and determine new and creative ways to develop collaborative solutions that reach across sectors, scales and places. While there is significant scholarly discussion on social movements aimed at transforming the dominant food system (Wittman, Desmarais, \& Wiebe, 2010; Goodman, DuPuis, \& Goodman, 2012; Levkoe, 2014), it is vital to continue documenting and critically assessing existing and innovative approaches to critical analysis and action. An underreported yet influential area of activity is the collaborations among students, faculty, and communitypractitioners building healthy, equitable, and sustainable food systems within post-secondary 
institutions and the ensuing implications for food movements more broadly (for example, see Rojas, Richer, \& Wagner, 2007; Andrée, Kepkiewicz, Levkoe, Brynne, \& Kneen, 2014; Levkoe et al., 2016).

This paper investigates the role that Community Service-Learning (CSL) can and does play in fostering food systems change. We examine how CSL can be used as a strategic lever for building healthy, equitable, and sustainable food systems that reflect contemporary research and experiences. To explore these opportunities, we draw on Planning for Change: Community Development in Action, a graduate level CSL course at the University of Toronto and a partnership with Meal Exchange, a Canadian non-profit organization, to support the development of the Good Food Challenge on college and university campuses across Canada. Using CSL to support social movements is not new; however, there has been little application of these pedagogical approaches within the field of food systems studies, especially in the area of campus food movements that engage diverse groups in mutually beneficial and transformative projects.

The description and analysis of our case study reflects the experiences of the three authors as project participants: Charles Levkoe, a Planning for Change course instructor, Sarah Archibald, Meal Exchange's Special Programs Coordinator, and Simon Erlich, a University of Toronto graduate student. Our description of the case study is organized into three categories that represent key spaces concurrent with CSL praxis: the classroom, the community, and spaces of engagement. Reflecting on these spaces, we demonstrate the potential of CSL to contribute to more robust food movements through vibrant academic and community partnerships. Together, these spaces express key outcomes as well as our learnings about the successes, and limitations of engaging in this kind of work.

We begin by providing an overview of the context of campus food systems, the campus as a site of movement building, and CSL as a contribution to social change. This will then be followed by a discussion of the three interrelated spaces of CSL - the classroom, the community and spaces of engagement — that introduce our case study. Through our discussion of the three spaces, we present a series of collective reflections alongside a critical analysis of the case study. In doing so, we suggest key lessons for ways that CSL can be a valuable tool for mobilizing around food system change as well as ways these learnings might apply to other CSL partnerships and progressive movements.

\section{Campus Food Systems}

Post-secondary institutions' food systems are comprised of a series of interdependent relationships that bring food to the plates of students, staff, faculty and other groups participating in activities on campus. Depending on the specific institution, this can include production, harvesting and procurement of food, processing/preparation, distribution, sales, and the management of food waste. Despite some exceptions, most campuses have become deeply immersed in the corporate, industrial food system underpinned by the dominant economic logic of "pushing product for profit" (Winson, 2013, p. 111). Saddled with the task of feeding a large population that is often isolated from other food sources, many campuses 
have settled for providing cheap, energy-dense, nutrient-poor food (Martin \& Andrée, 2012). This context provides a host of challenges and subsequent opportunities for critical analysis and action.

In the 2013-2014 academic year, there were over 2,000,000 students enrolled in 135 public colleges and 100 public and private not-for-profit universities across Canada (Statistics Canada, 2015). This represents almost $6 \%$ of the country's population. For many students living on campus, purchasing a meal plan is mandatory, and for universities and colleges located outside of an urban core, there are few other options to access food. These meal plans generally range in annual cost from $C A D \$ 500$ for a limited number of meals to $\mathrm{CAD} \$ 6,000$ for unlimited

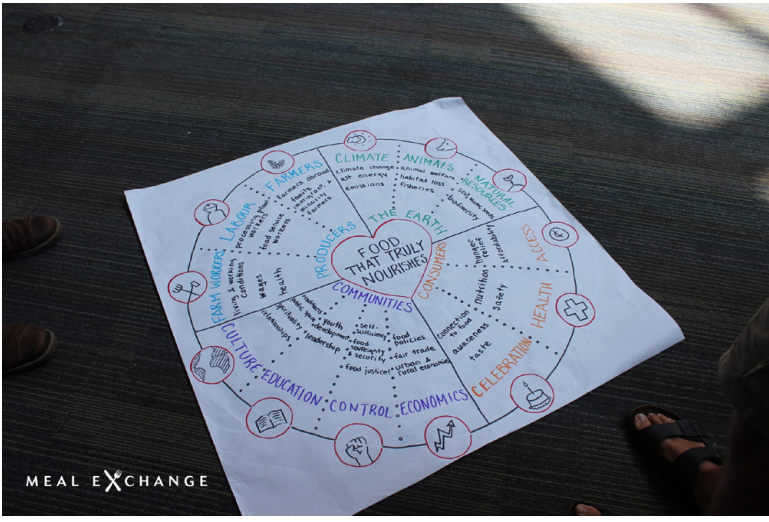

Meal Exchange's Good Food Wheel depicts the ways that "Good Food" can impact food systems, including producers, the earth, consumers and communities.

food access (CFS, 2013; University of Guelph Student Financial Services, 2017; University of Toronto Food Services, 2017; University of Victoria Food Services, 2017). Together this captive market contributes CAN $\$ 1.148$ billion dollars in sales from food services in Canadian educational institutions (fsStrategy, 2016).

The sheer scale, complexity, and logistical requirements of most of these operations have encouraged many post-secondary institutions to outsource the majority of their food services (Green \& Asinjo, 2015). In Ontario post-secondary institutions, over $75 \%$ of all food sales are subcontracted to large food service corporations, such as Aramark, Sodexo, and Compass Group (Peters, 2015; Mohawk College Sustainability Office, 2017). Food service corporations typically operate on a profit-loss model, and are responsible for ensuring profitability to their shareholders and clients (i.e., campus food services). This model affords significant decision-making control over key areas, including hours of operation, staffing, marketing, menu development, and food purchasing decisions. Glickman et al. (2007) found that "outsourcing has become a widely-accepted practice that provides substantial cost-saving benefits for institutions; this has become particularly important as the growth in funding for higher education has slowed and in some respects declined" (p. 440). According to Martin and Andrée (2012), corporate consolidation "has produced a highly concentrated institutional food sector" (p. 168), where any "new entrants to the sector are at a disadvantage because of the established economies of scale and supply chains, and most importantly, capital". Subcontracted corporations are able to maintain their domination of campus food systems by requiring prospective food service providers to pay for access to campuses (Burley et al., 2016). Once under contract with a corporate food vendor, control remains with the corporation, which results in more centralized supply chains, with food service providers reliant on cash 
rebates from large food manufacturers (Martin \& Andrée, 2012). This corporate food provision supports the industrial food system, in contrast to most college and university mandates of playing a leadership role in supporting local economies, promoting environmental stewardship, and considering the health and welfare of their campus population and the broader community.

Despite the problematic attributes of the corporate, industrial food system that proliferate on college and university campuses, there are opportunities to reimagine and change the role of food for post-secondary institutions. Many have argued that public universities are in a unique position, and have an obligation, to take a leadership role in creating local and sustainable food supply chains as a way to drive change (Friedmann, 2007; Pothukuchi \& Molnar, 2015). Stahlbrand (2016) argues that, "universities must respond to a client group-students-who increasingly demand values beyond price (including fair labour practices, environmental stewardship and animal welfare, among others) in food procurement and university policy generally" (p. 34). Further, Glickman et al. (2007) argue that incentives exist toward moving away from outsourcing food and that by keeping parts of the food system in-house, there is a potential for higher profits as well as greater flexibility and control over food purchasing and labour. Beyond their purchasing power, DeBliek, Strohbehn, Clapp, \& Levandowski, (2010) suggest that colleges and universities can also contribute valuable research, analysis and knowledge dissemination about alternative food systems within society more broadly. Initiatives that support localizing campus food systems not only provide a potential for food system change through education and knowledge dissemination, but also demonstrate that campuses represent powerful sites of social movement building.

Building on these kinds of opportunities, Meal Exchange is a Canadian non-profit organization that has been supporting students across Canada developing innovative solutions that address food insecurity and food system sustainability on campuses for over twenty-five years. Most recently, Meal Exchange's Good Food Challenge program has leveraged students, researchers, campus community members and food services, to push post-secondary food systems towards greater sustainability, community impact and social-wellbeing.

\section{The Campus as a Site of Social Movement Building}

Post-secondary institutions in North America have long served as spaces for social movement building with a dramatic expression of activism in the late 1960s addressing areas such as free speech, civil rights, and anti-war sentiments (Levitt, 1984; Barnhardt, 2014). While the sociopolitical issues that fuel today's campus activism have shifted, the recognition of campuses as locations of resistance and as drivers of change remains. Pothukuchi and Molnar (2015) argues, "Universities serve functions besides training young people for future employment, helping them develop their potential, and replicating society and culture; they also have roles in transforming society and creating more just arrangements" (p. 342). Doherty, Cawood, and Dooris (2011) adds that post-secondary education students and faculty have a unique opportunity to create change as "they not only have the capacity to make and embed changes to their own practice, but are also in a position to educate and facilitate learning towards global citizenship of the next generation of decision-makers" (p. 223). In short, colleges and 
universities are in a unique position to challenge dominant paradigms and to present new alternatives to critical present-day issues. Equipped with an engaged student population, supportive faculty, and a wealth of intellectual and financial resources, they have an opportunity to engage in critical thinking and experimentation with new practices. More recently, Canadian campus activism has focused on concerns regarding rising tuition costs and student debt, divestment from fossil fuel, access and

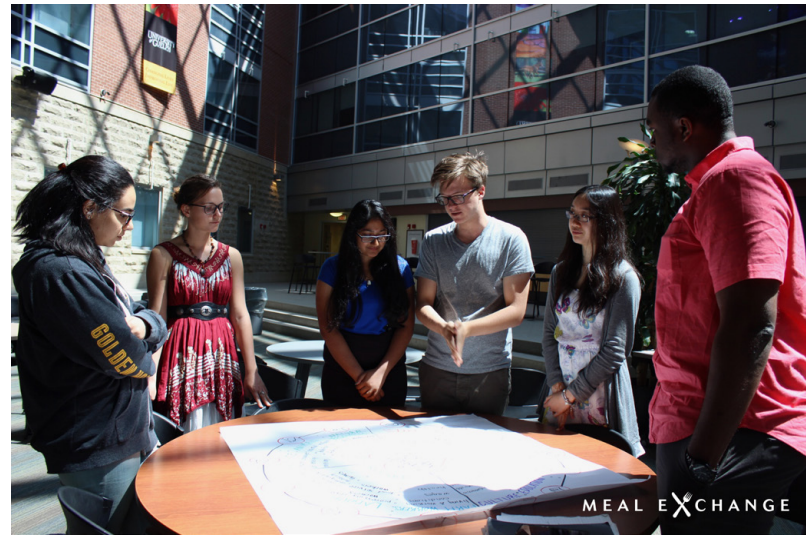

Students use Meal Exchange's Good Food Wheel to discuss food systems on their campuses opportunity for immigrant students, and sexual assault on campus (Barnhardt, 2014). Further, post-secondary campuses are held in general high-regard amongst the public and are often looked to for critical perspectives and solutions to social, economic and environmental challenges.

As food systems become an increasing point of contention, campus food movements have gained significant traction. According to Roberta Anderson of the U.S. Food Alliance (quoted in Barlett, 2017), "Colleges and universities are leading the sustainable food movement and have been for a while" (p. 189). Through food, students have been able to address a range of critical and interconnected social, economic, and ecological issues (Burley et al., 2016). Green and Asinjo (2015) agree that college and university campuses are an ideal catalyst for food system transformation for three reasons:

First, they nurture student engagement, raising questions of ethics and sustainability. Second, they can prioritize research, scholarship, and extension work on alternative food production and consumption. Third, they are central institutions that can impact economies by shifting some of their purchasing to local, fair, or sustainably produced foods" (p. 22).

There are a number of emerging examples of postsecondary institutions adopting sustainability principles within their food systems. Based on a study of campus food services across the United States, Barlett (2017) demonstrates, “[f]rom a general alternative food intentionality, some campuses have moved to comprehensive policies involving lists of desired criteria and websites naming farmers who supply the cafeteria" (p. 189). Campbell, DiPietro, and Remar (2014) show that students are increasingly willing to spend more money to access local and sustainable food products. This is supported by research from Meal Exchange's Campus Food Report Card, which noted that $80 \%$ of student respondents felt it was important for their campus to source and provide sustainably-grown foods (Maynard, Lahey, \& Abraham, 2018). A study 


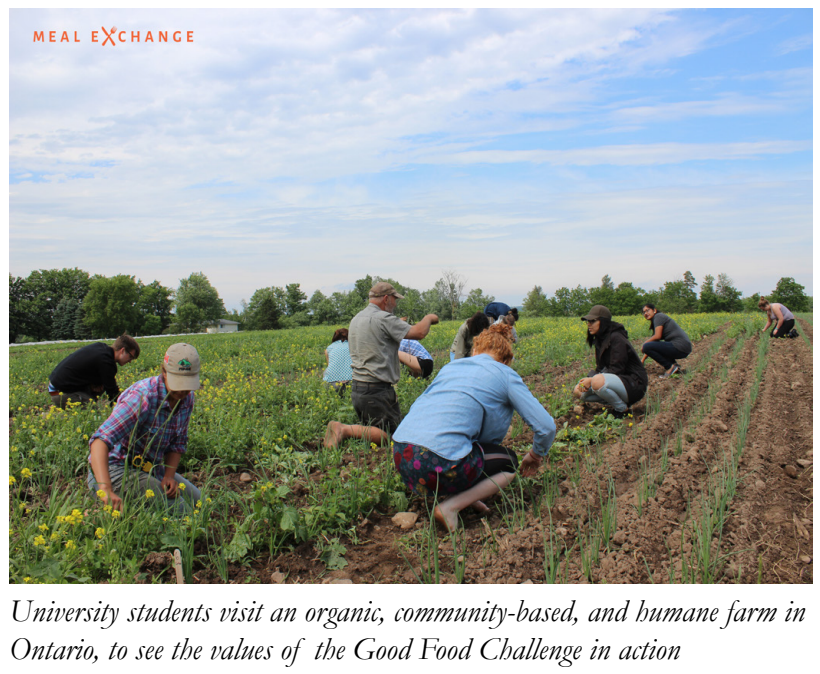

from Mohawk College Sustainability Offices (2017) showed that over 85\% of students surveyed believed that it was important to serve local food on campuses as a contribution to sustainability initiatives. Studies have also documented numerous examples of students driving alternative food systems, including the establishment of campus farmers markets, gardens, food cooperatives, and food justice initiatives (Berg, Ciotobaru, \& Pirri, 2014). Barlett (2011) observes there is also a growing movement amongst post-secondary campuses towards sustainable food systems as demonstrated by the number of institutions with formal commitments to sustainable food purchasing. At the University of Toronto, a partnership with Local Food Plus in 2006, required corporate food providers to use local and sustainable products for an increasing portion of its 60,000 students' meals (Friedmann, 2007). Since 2007, the Real Food Challenge in the U.S. has been mobilizing students to secure commitments from campus Presidents to include $20 \%$ or more "real food" (e.g., food that is healthy, equitable and sustainability) by 2020 . As of late 2017 , over 40 campuses pledged to shift more than US $\$ 60,000,000$ in food purchasing towards "real food" (The Real Food Challenge, n.d.) and ten University of California campuses have already met the $20 \%$ goal (Thill, 2017). This largescale national campus mobilization provided the model for Meal Exchange to develop the Good Food Challenge, recognizing how campus procurement provides substantial economic, ecological and social impacts across the country (Porter, 2015). Building on popular momentum for food systems work along with the unique positioning and capacities of colleges and universities, CSL presents an important opportunity to maximize the benefits of campuses as sites of social movement building.

\section{Community Service-Learning and Social Change}

CSL involves the interweaving of classroom instruction and community service in an effort to bridge learning around both theory and action (Chambers, 2009). Unlike volunteering or internships, CSL is a pedagogical model where students engage in ongoing critical reflection that connects theoretical learning and community-based experiences (Bringle \& Hatcher, 1996). This approach demands strong curricular connections, as well as the need to provide mutual benefit to both students and community partners. Butin (2010) identifies CSL as having the potential to be a key form of academic engagement, as well as a tool for building civic responsibility. CSL has its roots in experiential and liberatory education (Freire, 1970; Hayes, 2011) and has been hailed as an engaged pedagogical approach that has the potential to 
develop students' skills, critical thinking and self-discovery along with supporting community needs (Knapp, Fisher, \& Levesque-Bristol, 2010; Greenwood, 2015).

CSL increasingly connects with, and contributes to a range of social movements (for example, see Corteau, Haynes, \& Ryan, 2005; Hayes, 2011). Many scholars have documented ways that CSL can be a democratizing and counterhegemonic practice that challenges unjust power relations, making the university a key site of struggle (Cipolle, 2004; Mitchell, 2008; Porfilio \& Hickman, 2011; Cahuas \& Levkoe, 2017). Bickford and Reynolds (2002) explain that CSL can "give learners a broader understanding of dissent and will encourage them to envision themselves as actors or agents in political arenas" (p. 30). Hayes (2011) describes this potential as "experiential learning that empowers people to recognize, expose and eradicate the social injustices that structure their lives within a hegemonic social order" (p. 11). While many students come to post-secondary education with idealistic intentions to promote social change, CSL can help facilitate practical and aspirational momentum, ground ideas in realworld issues, and contribute administrative and intellectual support for guidance and viability (Burley et al., 2016).

In this paper, we build on this context to demonstrate ways that CSL can be a valuable and strategic tool for developing meaningful partnerships to impact campus food systems and as a site for broader social movement building. Our analysis of the partnership developed between Planning for Change and Meal Exchange demonstrates the ways that theory attained in the classroom and practice in the community intersect through spaces of engagement. Through an analysis of our case study of the Good Food Challenge in Canada, we argue that it is the interconnection of these three spaces where the greatest impact is made.

\section{Spaces of Analysis: Planning for Change, Meal Exchange, and the Good Food Challenge}

The examination of our case study is based on reflections and analysis of our collective experience focusing on three spaces representing the key sites of theory, practice and reflection of CSL: classroom spaces, community spaces, and spaces of engagement. Our reflection involved a process of collaborative autoethnography that included individual self-reflection, as well as inter-subjective analysis of our shared experiences (Chang, Ngunjiri, \& Hernandez, 2016). We used this approach to explore our own experiences in relation to each other and to our academic and community-based colleagues, through two conference presentations and sharing drafts of this paper. The information provided in this section is a synthesis of these reflections.

\section{Classroom spaces}

The first space describes what happened in the classroom, focusing on the activities that took place primarily within the Planning for Change seminars and the interaction with theory and ideas.

Planning for Change is an eight-month, graduate-level CSL course based in the Department of Geography and Planning at the University of Toronto. The course consists of in-class 
seminars, as well as each student being placed — as an individual or as part of a group—within a community-based organization. Work with the community partner occurred as an additional commitment to the course work at approximately five hours per week. Planning for Change has been offered five times since 2011 and has worked with over eighty students and forty different community partners. The participating community partners are primarily non-profit organizations with an explicit mandate that incorporate the course's three core themes: social justice, civic engagement, and community development. Originally established by faculty as a way to engage with community-development initiatives in the City of Toronto, Planning for Change depends on the support of the university's Centre for Community Partnerships and the commitment of the community partners that contribute their valuable time and knowledge to the CSL process. The course's objectives are to enable students to gain practical experience, assist community groups to design and implement projects chosen by the community itself, reflect critically on their education and their role as a student and citizen, and to build longerterm commitments to communities and neighbourhoods throughout Toronto (for other descriptions of Planning for Change see Levkoe, Brail, \& Danier, 2014; Levkoe, Friendly, \& Danier, 2018.

Theories examining the merits and limitations of CSL, the issues of political economy, social justice, and community development were integrated through the provision of weekly course readings and assignments. This took the form of salient topics related to the political, economic, and social contexts that structure community development, as well as research methods and other skills related to working with community partners. For example, topics included discussing state restructuring and the subsequent growth of the non-profit sector, cultural and racial diversity in the city in relation to students' research and placements, democracy and civil-society engagement, community-based participatory action research, and advocacy in the context of community development. After initial lectures, students engaged in group discussions where they would be given the opportunity to reflect on their projects and experiences in light of the theoretical concepts presented through the readings. This provided reinforcement for the content of the readings while also promoting reflection on how concepts related to their placement experiences. Students enrolled in Planning for Change represented a variety of disciplines and backgrounds, which provided a diversity of expertise and skills for community partners. In the case of Meal Exchange, students came with practical and academic training in public health, geography and community planning.

The structure of the classes also helped to ensure productive work was being carried out in an achievable and equitable way. At the beginning of the course, students, instructors and the community partners developed a Collaboration Agreement to ensure clear expectations, an attainable work plan and a framework for accountability. Further, a timeline was developed to facilitate open communication help ensure that the work was achievable and to provide all partners with a roadmap of expected deadlines. Throughout the eight-months of the course, community partners were invited to attend seminars, give guest lectures, and select course readings and topics. For example, on multiple occasions, representatives from the partner organizations joined the class to provide presentations on key topics and to participate in 
discussions. On other occasions, the students met at a particular organization's workplace to participate in tours and engage with community members through films and presentations. This enabled community partners to influence classroom learning as well as offer insight into specific challenges they encountered in their daily work. This process required significant flexibility and willingness to adapt on the part of the course instructors and students.

The classroom space also facilitated sharing campus resources with community partners including access to peer reviewed journals, books, and new research. Having access to the vast university library system at the University of Toronto was of particular value for the Good Food Challenge - the research demanded academic integrity and the accessing of a variety of resources that would have put significant financial stress on a small non-profit organization. The classroom also offered the opportunity for awareness building, support, and constructive criticism for students' projects. This was facilitated via updates provided to classmates throughout the year, informal conversations and reflections that happened both during and after classroom activities, and — most prominently-through presentations given at the course's conclusion. In some instances, these conversations led to suggestions for new ways of thinking about the projects as the students enrolled in Planning for Change had varying degrees of familiarity with the issues. Outside of providing an avenue to receive constructive feedback, sharing information required the students to prepare the research in a way that was accessible to an audience not familiar with the project. These interactions furthered awareness of the Good Food Challenge and its goals to an audience of highly engaged burgeoning academics and professionals. This also helped to mobilize the work of Meal Exchange and its goals of food system change through increased awareness, engagement, and student mobilization.

\section{Community spaces}

The description of the community space focuses on practice - the work that took place with Meal Exchange. Through Planning for Change, each graduate student was placed with a community partner after a matching process that assessed their skills and interests in relation to the needs of the organization. This process involved students selecting their top choices (after reviewing project descriptions) and meeting the community partners in-person during the first class. Instructors then conducted one-on-one interviews with each student to discuss why they would be a good fit within the selected placement. The instructors spent time during the summer months building relationships with different organizations to develop the projects and thus, understood what each position required. Many of the partnerships were based on preexisting relationships through the instructors' research and community work. In the case of Meal Exchange, Charles Levkoe had worked with staff in the past and was familiar with the organization's work and approach.

Since 1993, Meal Exchange has worked to mobilize post-secondary students across Canada to build healthier, more equitable and sustainable food systems. Meal Exchange's programs address issues of food insecurity, social justice, and environmental sustainability across the food value chain, starting with the campus food system. With more than 40 universities and 
colleges involved in the Meal Exchange network, campuses serve as both the living laboratory for students to run programs, and as a potential model for other public institutions such as hospitals and municipalities. Over 100,000 students are reached by these efforts each year and over 6,000 students volunteer through participating in or running programs and providing valuable research through community-campus partnerships. The common thread throughout Meal Exchange's history has been to engage students' motivation for social change, taking advantage of academic potential and creating viable models of healthy, equitable, and sustainable food systems.

Recognizing the purchasing power that campuses have, and the subsequent impacts on other sectors and institutions, Meal Exchange developed the Campus Food Systems project in 2011. The Campus Food Systems project brought together campus administrators, students, faculty, food services, and local organizations to shift procurement toward more local and sustainable food systems. While this project gained localized success on specific campuses, Meal Exchange aspired to develop a program that could be scaled-out to every campus across the country. Looking to the US's Real Food Challenge as a model for national-scale impact, Meal Exchange staff began discussions with their US allies to understand how the campaign was being used to measure and shift US\$1 billion of campus food budgets towards pillars of local and community-based, fair, ecologically-sound, and humane food (Real Food Challenge, n.d.). With the strong relationships and networks that Meal Exchange had created, they decided to adapt the Real Food Challenge project to reflect the context of campus food systems in Canada. In doing so, the organization established that it needed to: (i) craft position papers to outline the pillars of student values to develop "Good Food Standards"; and, (ii) review all certifications and agricultural programs in Canada to develop the Good Food Guide of acceptable products. The position papers, needed to reflect the latest research and experiences from all actors across food systems. Recognizing the importance of appropriately adapting the Real Food Challenge program to the Canadian cultural, ecological, and political landscape, dedicated researchers and writers with significant knowledge, skills and capacity were needed. Meal Exchange turned to an existing partnership with Planning for Change to garner support for a series of position papers that would establish the foundation for the Good Food Challenge in Canada.

The primary tasks of the Planning for Change students were to research, develop, and draft a series of position papers building on the four pillars from the US Real Food Challenge: (a) Community-Based Action, advocating for supporting local producers and businesses and creating community connections between consumers and producers; (b) Social Justice, acknowledging and advocating for the improvement of wage gaps and poor working conditions existing within the mainstream food system; (c) Ecologically-Sound Practices, seeking to promote food products that are environmentally sustainable; and, (d) Humane Treatment, acknowledging the often poor treatment of animals raised for food production and advocating for more humane treatment. 
To create the four positions papers ${ }^{1}$, students needed to understand the organizational context of Meal Exchange and the overall objectives and goals of the Good Food Challenge. Through Planning for Change, students spent time connecting with a wide range of individuals involved in the Meal Exchange network, including other students across Canada, local producers, activists, and members of partner organizations involved in different food systems work. These connections helped provide the information needed to develop a research outline for the position papers within the Canadian context. Meal Exchange staff provided the students with foundational documents, including the original US positions papers and organizational strategy documentation to support the research. Each draft paper consisted of rigorous academic research, which leveraged the graduate-student's research skills, integrated with food movement values, tangible qualifiers for assessing different food products, and connections with existing third-party certifications that align with the qualifiers. The position papers were then reviewed by a group of scholars, community partners, and students with experience relevant to each individual paper. The position papers defined a list of formal criteria that eventually became the Good Food Guide; this in turn became the basis for the Good Food Calculator, a tool used for auditing food procurement dollars on campuses.

Beyond the research being conducted and the advancement of the Good Food Challenge, the community space offered both students and Meal Exchange staff a range of professional development experiences. For example, students gained exposure to the realities of working in the non-profit sector, practical research skills beyond the academy, and built valuable networks with other students, professors, and practitioners in the field. Meal Exchange staff gained practical management experience as they were tasked with supervising students, conducting evaluations, and organizing multiple schedules. In addition, staff was exposed to new academic networks and research methods that played a key role in their ongoing work.

\section{Spaces of engagement}

Spaces of engagement are spaces where classroom learnings and community actions intertwine. While internships and volunteer placements are able to offer learning in the community, and traditional post-secondary education courses focus on learning in the classroom, it is through critical praxis that CSL has the power to impact participants and society more broadly.

Spaces of engagement were made possible by the way Planning for Change students integrated theory acquired from in-class lectures, readings, and discussions into their community placements, and vice versa. Students applied their learnings to have more tangible impacts through a process of critical praxis - the intersection where theory and practice opens the possibility for both personal learning and social change (Wakefield, 2007). One salient example of critical praxis took the form of students leveraging their previous classroom knowledge to assess and address concerns about health, equity, and sustainability within food supply chains. This was most evident in the development of positions papers that embodied an intersection of both theory and practice, as the students were able to find and integrate literature they

\footnotetext{
${ }^{1}$ Meal Exchange has since worked with a team of students to write two additional papers on pillars of Sustainable Seafood
} and Food Sovereignty. 
had gained exposure to through their current and previous academic training. Each paper combined thorough literature reviews and background research, along with a scan of existing certifications and initiatives to shift the value proposition of campus food systems. Through classroom learning, research, and practice, students were able to support the Good Food Challenge by leveraging their academic experiences.

Another example of critical praxis within the spaces of engagement was students' awareness of the broader context within which Meal Exchange was working. Specifically, course readings addressed issues surrounding the neoliberalization of the non-profit sector (see Trudeau, 2009), which were reinforced through observations of Meal Exchange's dependence on highly competitive grant funding and increasing responsibility towards social justice and ecological sustainability to fill a void left by government cutbacks (Peck \& Tickell, 2002). By utilizing weekly reflection assignments and bringing these observations into classroom discussions, the students were better able to contextualize not only the need for non-profits to provide vital social functions, but also the ways they can relieve pressure on developing structural changes. This also enabled the students and Meal Exchange staff to apply these critical ideas to the development and implementation of the Good Food Challenge.

A key component of CSL that shaped spaces of engagement was the use of critical reflection techniques to make sense of the experiences, in relation to the different spaces students moved through during the course. This was done formally through integrating class assignments and community outputs using various tools (both oral and written), and informally through conversations with other students, instructors, and community partners. Instructors provided feedback through one-on-one meetings with students, in-class conversations, e-mails, and through class assignments. Community partners also provided students with regular feedback during placements via weekly meetings, along with written evaluations to instructors.

For the Good Food Challenge, leveraging various forms of feedback became an integral method for the advancement of the position papers. Instructors had specific interest and expertise in the area of sustainable food systems, and were able to provide input, suggest resources, broker connections to other academics or community groups involved in related work, and edit and provide constructive feedback on the position papers. Graduate students were able to use experiences from their academic training to improve the quality of their work and, as a result, were better able to meet the needs of the project.

Overall, Planning for Change played a vital role in the development of the Good Food Challenge in Canada. Beyond the direct contributions from the CSL course, Meal Exchange has continued to engage students in contributing academic knowledge and skills through a variety of means: other CSL courses, independent research projects, summer job programs, and volunteer positions. With the support of the Planning for Change partnership, Meal Exchange established a strong foundation for the project and was able to leverage its expertise in student engagement and multi-stakeholder collaboration to pilot the Good Food Challenge at fourteen campuses across Canada in 2017. Through this pilot, students audited over CA $\$ 12,500,000$ of campus food procurement budgets and provided a number of recommended shifts in procurement. 


\section{Discussion}

\section{Course successes}

Through the preceding discussion of the three spaces of analysis, we have described the ways CSL has played an important role in the partnership between Planning for Change and Meal Exchange in supporting the development of the Good Food Challenge. This partnership demonstrates how campus-based food movements and community-academic collaborations can act as strategic levers in shifting towards more healthy, equitable, and sustainable food systems. In general, we found the expertise students brought to their work contributed valuable knowledge to the direction of the Good Food Challenge, both in respect to the immediate outputs and to the development of new and existing relationships. It was also extremely valuable for the students' personal learning and professional development-they were able to conduct applied research on a topic of interest, find an avenue to use their academic skills in a practical and meaningful way.

These collective reflections point to the importance of Planning for Change, and CSL more broadly, in acting as a broker in relationships between community and academic partners and the private sector. The extension of localized campus action and knowledge to a national network of campuses and social movements allowed the integration of theoretical concepts and practical action to go well beyond the learning taking place in the traditional classroom. These partnerships also facilitated introductions to leading researchers and organizations in each of the Good Food Challenge's position paper topics.

Moreover, this specific CSL experience prepared Meal Exchange staff to engage in effective academic partnerships with other courses and independent student researchers. In turn, this helped ensure realistic expectations of outcomes and more meaningful engagements for students and faculty. In the case of Planning for Change, this was made possible through long-term relationships developed between community and academic partners and their commitments to collaboration. An eight-month course provided a timeframe that enabled a substantial amount of work to be accomplished, and for Meal Exchange staff to work closely with students to identify their skills and interests. Meanwhile, the students were able to become acquainted with the work of the community partner in-depth. Building off the success of Planning for Change, Meal Exchange has continued to work closely with hundreds of students and instructors across Canada to provide feedback on the Good Food Challenge position papers and related materials.

The strength of these relationships is demonstrated through work that is community driven, student-led, academically informed, and tested back in the community. The partnership between Planning for Change and Meal Exchange established the foundation for the Good Food Challenge in Canada. With access to the knowledge and skills of students, faculty, and university resources, the Good Food Challenge has played a key role in significantly increasing the critical analysis of the dominant Canadian food system while demonstrating viable alternatives.

Analysts have argued that building social movements around food systems change 
requires multi-sectoral engagement that can benefit immensely from academic and community partnerships (Levkoe, 2014; Andrée et al., 2016). As demonstrated through this case study of Planning for Change, strong relationships were established based on personal connection and shared interests in sustainable food systems predating the course, and will likely continue into the future. Additionally, the commitment of the students, instructors, and Meal Exchange staff went well beyond the eight-month timeframe of the project. This is not always possible or even realistic within the structure of a CSL course. Relationships developed through Planning for Change, were more than a simple coincidence, as all participants put extensive effort into moving the relationships in this direction. For Meal Exchange, the partnership was based on open communication regarding the requirements of the course (in respect to the students' needs), but also allowed organizational staff to take the lead in determining the project's direction. This meant both instructors and students needed to be extremely flexible and open to the realities of the project.

\section{Course issues}

Despite these successes, there were also a number of tensions that demanded patience and commitment. We identified three key tensions that arose in the work through Planning for Change.

First, one of the most prominent tensions was the reality that both community and academic partners were working with very limited resources. Instructors were obligated to take on more organizational and logistical supports beyond the typical requirements of a graduate-level course. For a non-profit organization, taking on CSL students is a major investment that, in this context, consisted of many hours of preparation and review each week and more support at certain times by Meal Exchange staff, to ensure that research and student contributions were on track with the organizational vision and timelines. Limited time made it difficult for students to participate in the full culture of the organization, which could have been an important learning for the students but also increased their ability to conduct productive and meaningful work. In many cases, students were not able to see projects through to completion, unless they volunteered their own time after the course finished (and this did happen in many cases). Moreover, it can be challenging to consistently train new students every year to integrate into an organization. Having an ongoing relationship through CSL, however, does create easier and more efficient transition as the community and academic partners become more familiar with the dynamics of the partnership.

Second, a tension emerged from asymmetries in students' understandings of, and commitment to, social justice and how it should be applied. While some students entered Planning for Change with strong backgrounds in community development and a theoretical understanding of intersectionality and oppression, there were many students that had not previously considered these ideas. This lead to differences in student motivations for working with a community partner engaged in social change efforts, and misunderstandings of objectives, goals, and critical theory in relation to the practical work being completed. For example, some students were explicit that they joined Planning for Change looking for 
employment skills, and were less interested in the transformative potential of the CSL work.

Third, tensions arose around the radical goals of critical pedagogy, as expressed through the intersection of critical theories discussed in class and the instrumental needs of community partners. In some cases, this led to feelings of dissonance and/or disappointment expressed by the students, feeling their work was limited by the immediate requirements of community partners or funders. For example, students often struggled with how to apply critical perspectives of non-profit organizations while also working with and supporting day-to-day operations. This tension relates directly to the challenge of doing transformative work in a neoliberal environment dependent on strategic alliances and competitive fundraising. In the context of the Good Food Challenge, students faced dissonance between the work they were doing and the more radical goals of critical literature they read throughout their university courses. This tension between radical and reformist approaches is also present in debates about food movements at the global scale (Holt-Giménez \& Shattuck, 2011).

\section{Conclusion}

In conclusion, this paper has explored the value of CSL as a pedagogical tool and its contribution to food system change as exemplified through the relationship between Planning for Change, Meal Exchange, and the Good Food Challenge. CSL is unique for its ability to intertwine classroom learning and community action. The intersection and engagement of these spaces is what enables for critical praxis and, ultimately in our context, the development of campus food movements. This is demonstrated through Meal Exchange's adaption of the US Real Food Challenge, mobilizing faculty and students around sustainable food procurement on Canadian college and university campuses. The work conducted through a collaboration of graduate students, a community partner, and two instructors laid the foundation for the Good Food Challenge to flourish in the Canadian social, ecological, and economic context, alongside support from supply-chain corporations, peer organizations, and funders.

As a result of these collaborations, the Good Food Challenge has been piloted on campuses across Canada and, with the support of new partnerships, continues to grow. Behind the successes of this program are the dedicated efforts of staff, students, campus food service providers, and faculty at each campus supporting the research, evaluation, and auditing of campuses food procurement. The pilot phase auditing work that occurred during the writing of this paper provided insight into the current level of 'good food' purchased at these campuses. It also created a baseline from which campuses can strive to improve their food purchasing to meet the health, equity, and sustainability criteria developed in the position papers. As an outcome of the partnership with the Planning for Change CSL class, the Good Food Challenge is becoming a driving force for shifting food procurement on college and university campuses and for campus food movements more broadly.

As the Good Food Challenge expands, it has become less reliant on one-off CSL partnerships to complete primary tasks and connect actors. However, it is important to highlight the instrumental value CSL has had in building campus food movements. The CSL partnership through Planning for Change helped take advantage of students and instructors with extensive 
networks who were presently working on food system issues within academic and non-profit sectors. For example, the instructor was able spread awareness of the Good Food Challenge to colleagues who could then further disseminated awareness to students. These students, in turn, spread awareness about the initiative on their own campuses and, through connections with other students, at other campuses. Faculty members were also able to become involved through reviewing the position papers and providing feedback. Students and faculty together created localized Good Food Challenge initiatives using the model created by CSL students and Meal Exchange (both independently and through course work), contributing to the larger food movement. To date, over 200 individuals have been involved in the creation of the Good Food Challenge standards including students, faculty, elders, farmers, food services members, and partner organizations, all coordinated by Meal Exchange.

\section{CSL as a model for program dissemination and continuation}

This model using CSL as a tool of knowledge co-creation and connectivity could be replicated to work with other progressive movements. Issues common across campuses such as rising tuition fees and fossil fuel divestment represent current examples that could be addressed (and indeed, are being implemented already). Key lessons for mobilizing around food system change require acknowledgement of the diverse actors within food systems and their sometimescontrasting goals. While food service providers are often profit-driven, this doesn't exclude them from a willingness to reimagine their food procurement strategies to more closely meet the demands of their customers (in this case, predominantly students). As such, for change to happen, campus food system actors must first be provided with a platform to begin discussing what campus food system should look like, and then how a consensus can be reached to bring mutual benefits. The Good Food Challenge provides such a platform by integrating the voices of food producers, actors within the food services industry, non-profit organizations, and academics. Further, collaborations among students, faculty, and community practitioners provide an important leverage point for building healthy, equitable, and sustainable food systems within post-secondary institutions — and for food movements more broadly.

\section{Acknowledgements}

We gratefully appreciate the patience and perseverance of the students and community partners who have made Planning for Change: Community Development in Practice possible over successive years. Thank you to Amrita Daniere for contributions to the Planning for Change course and for the ongoing intellectual stimulation, and to Anita Abraham for her feedback on the draft manuscript. 


\section{About the Authors}

Sarah Archibald is the past Program, Operations, and Opportunities Manager with Meal Exchange. She learned from the wisdom of food gathers and growers in seven countries and many nations across Turtle Island. She is currently a graduate student at the University of Toronto and continues to work part-time at Meal Exchange.

Simon Erlich is a former graduate student in geography at the University of Toronto. His research evaluates the transformative potential of retail food cooperatives and their contribution to an alternative food system. He has developed an extensive background in food system studies having also undertaken an undergraduate degree in environmental geography.

Charles Z. Levkoe (corresponding author) is the Canada Research Chair in Sustainable Food Systems and assistant professor in the Department of Health Sciences at Lakehead University. His community-engaged research uses a food systems lens to better understand the importance of, and connections between social justice, ecological regeneration, regional economies and active democratic engagement. E-mail: clevkoe@lakeheadu.ca

\section{References}

Akram-Lodhi, A.H. (2013). Hungry for change: farmers, food justice and the agrarian question. Halifax: Fernwood.

Andrée, P., Kepkiewicz, K., Levkoe, C., Brynne, A., \& Kneen, C. (2016). Learning, food and sustainability in community-campus engagement: teaching and research partnerships that strengthen the food sovereignty movement. In Sumner, J. (Ed.). Learning, food and sustainability: sites for resistance and change, (pp. 133-154). New York: Palgrave Macmillan.

Andrée, P., Chapman, D., Hawkins, L., Kneen, C., Martin, W., Muehlberger, C., Nelson, C., Pigott, K., Wajma, Q., Scott, S., \& Stroink, M. (2014). Building effective relationships for communityengaged scholarship in Canadian food studies. Canadian Food Studies/ La Revue Canadienne Des Études Sur L'alimentation, 1(1), 27.

Barnhardt, C. (2014). Campus-based organizing: tactical repertoires of contemporary student movements. New Directions for Higher Education, 167, 43-58.

Barlett, P. (2011). Campus sustainable food projects: critique and engagement. American Anthroplogist, 113(1), 101-115.

Barlett, P. (2017). Campus alternative food projects and food service realities: alternative strategies. Human Organization, 76(3), 189-203.

Berg, D., Ciotobaru, S., \& Pirri, M. (2014). On campus food systems: production, distribution, and best practices. Farm to Cafeteria Canada. Retrieved from http://www.farmtocafeteriacanada. ca/2014/11/on-campus-food-systems-production-distribution-and-best-practices/ 
Bickford, D. M., \& Reynolds, N. (2002). Activism and service-learning: reframing volunteerism as acts of dissent. Pedagogy, 2(2), 229-252.

Bringle, R.G., \& Hatcher, J.A. (1996). Implementing service learning in higher education. The Journal of Higher Education, 67(2), 221-239.

Burley, D., Coker, E., May, B., McCarty, T., Dickerson, E., Milligan, B., Moses, D., Sanchez, S., \& Hortman, R. (2016). Taking the challenge for real food: student engagement in procuring sustainability produced food on campus. Journal of Agriculture, Food Systems, and Community Development, 7(1), 71-87.

Butin, D. (2010). Service-learning in theory and practice: the future of community engagement in higher education. New York: Palgrave.

Campbell, J., DiPietro, R., \& Remar, D. (2014). Local foods in a university setting: price consciousness, product involvement, price/quality inference and consumer's willingness-topay. International Journal of Hospitality Management, 42, 39-49.

[CFS] Canadian Federation of Students - Ontario. (2013). Task force on campus food services: a look at food accessibility and affordability in Ontario. Retrieved from http://cfsontario.ca/ wp-content/uploads/sites/50/2015/12/CFS-2013FoodReport.pdf

Cahuas, M.C., \& Levkoe, C.Z. (2017). Towards a critical service learning in geography education: exploring challenges and possibilities through testimonio. Journal of Geography in Higher Education, 41(2), 246-263.

Chambers, T. (2009). A continuum of approaches to service-learning within Canadian postsecondary education. Canadian Journal of Higher Education, 39, 77-100.

Chang, H., Ngunjiri, F., \& Hernandez, K. (2016). Collaborative autoethnography. Walnut Creek: Routledge.

Cipolle, S. (2004). Service-learning as counterhegemonic practice: evidence pro and con. Multicultural Education, 11(3), 12-23.

Corteau, D., Haynes, W., \& Ryan, C. (2005). Rhyming hope and history: activists, academics and social movements. Minneapolis: University of Minnesota Press.

DeBliek, S., Strohbehn, C., Clapp, T., \& Levandowski, N. (2010). Building food service staff familiarity with local food. Journal of Hunger and Nutrition, 5, 191-201.

Doherty, S., Cawood, J., \& Dooris, M. (2011). Applying the whole-system settings approach to food within universities. Perspectives in Public Health, 131(5), 217-224.

Feenstra, G.W. (1997). Local food systems and sustainable communities. American Journal of Alternative Agriculture, 12(1), 28-36.

Freire, P. (1970). Pedagogy of the oppressed. New York: Seabury.

Friedmann, H. (2007). Scaling up: bringing public institutions and food service corporations into the project for a local, sustainable food system in Ontario. Agriculture and Human Values, 24(3), 389-398.

fsStrategy (2016). Canadian institutional food service market report. Retrieved from http://www. restaurantscanada.org/wp-content/uploads/2016/07/2016-Canadian-Institutional-

Foodservice-Market-Report-Abridged-Sample.pdf

Glickman, T., Holm, J., Keating, Devlin., Pannait, C., \& White, S. (2007). Outsourcing on American campuses: national developments and the food service experience at GWU. International Journal of Education Management, 21(5), 440-452. 
Goodman, D., DuPuis, E. M., \& Goodman, M. K. (2012). Alternative food networks: Knowledge, practice, and politics. New York: Routledge.

Green, A., \& Asinjo, R. (2015). Applying anthropology to the campus dining system: reflections on working with community food assessments and the real food challenge. Practicing Anthropology, 37(2), 22-26.

Greenwood, D.A. (2015). Outcomes of an academic service-learning project on four urban community colleges. Journal of Education and Training Studies, 3(3), 61-71.

Hayes, K. (2011). Critical service-learning and the black freedom movement. In Porfilio, B. \& Hickman, H. (Eds.). Critical service-learning as revolutionary pedagogy: a project of student agency in action, (pp. 47-69). Charlotte: Information Age Publishing.

Holt Giménez, E., \& Shattuck, A. (2011). Food crises, food regimes and food movements: rumblings of reform or tides of transformation? The Journal of Peasant Studies, 38(1), 109-144.

Knapp, T., Fisher, B., \& Levesque-Bristol, C. (2010). Service-learning's impact on college students' commitment to future civic engagement, self-efficacy, and social empowerment. Journal of Community Practice, 18(2/3), 233-251.

Levitt, C. (1984). Children of privilege: student revolt in the sixties: a study of student movements in Canada, the United States, and West Germany. Toronto: University of Toronto Press.

Levkoe, C. (2014). The food movement in Canada: a social movement network perspective. Journal of Peasant Studies, 41(3), 385-403.

Levkoe, C.Z., Andrée, P., Bhatt, V., Brynne, A., Davidson, K., Kneen, K., \& Nelson, E. (2016). Collaboration for transformation: community-campus engagement for just and sustainable food systems. Journal of Higher Education Outreach and Engagement, 20(3), 32-61.

Levkoe, C.Z., Brail, S., \& Daniere, A. (2014). Engaged pedagogy and transformative learning in graduate education: A service learning case study. Canadian Journal of Higher Education, 44 (3), 68-85.

Levkoe, C.Z., Friendly, A., \& Daniere, A. (2018). Community service learning in graduate planning education. Journal of Planning, Education and Research.

Martin, S.J., \& Andrée, P. (2012). The "buy local" challenge to institutional foodservice corporations in historical context. Journal of Agriculture, Food Systems, and Community Development, 2(3), 116175.

Maynard, M., Lahey, D., \& Abraham, A. (2018). Campus Food Report Card: The State of Food on Ontario University campuses. Retrieved from https://www.mealexchange.com/reportcard/

Mitchell, T.D. (2008). Traditional vs. critical service-learning: engaging the literature to differentiate two models. Michigan Journal of Community Service Learning, 14(2), 50-65.

Mohawk College Sustainability Office. (2017). Increasing local food procurement at Ontario's 24 colleges: the evolution of campus food services. Retrieved from https://www. mohawkcollege.ca/about-mohawk/initiatives/sustainability/local-food

Peck, J., \& Tickell, A. (2002). Neoliberalizing space. Antipode, 34(3), 380-404.

Peters, D. (2015). The campus food revolution. University Affairs. Retrieved from http://www. universityaffairs.ca/features/feature-article/the-campus-food-revolution

Porfilio, B., \& Hickman, H. (Eds.). (2011). Critical service-learning as revolutionary pedagogy: a project of student agency in action. Charlotte: Information Age Publishing Inc. 
Porter, J. (2015). Get real: an examination of the Real Food Challenge at the University of Vermont. Unpublished Thesis, University of Vermont. Retrieved from http://scholarworks.uvm.edu/ graddis/412/

Pothukuchi, K., \& Molnar, S.A. (2015). Sustainable food systems at urban public universities: a survey of U-21 universities. Journal of Urban Affairs, 37(3), 341-359.

Real Food Challenge. (n.d.). The Real Food Challenge. Retrieved from http://www.realfoodchallenge. org/

Rojas, A., Richer, L., \& Wagner, J. (2007). University of British Columbia food system project: towards sustainable and secure campus food systems. EcoHealth, 4, 86-94.

Stahlbrand, L. (2016). A typology of "infrastructure of the middle" in university food procurement in England and Canada: elaborating the "to" in "farm to cafeteria." Raizes, 36(2), 32-44.

Statistics Canada. (2015). Postsecondary enrolments by institution type, registration status, province and sex. CANSIM, table 477-0019. Retrieved from http:/ /www.statcan.gc.ca/tablestableaux/sum-som/101/cst01/educ71a-eng.htm

Thill, S. (2017). Building a sustainable food system, one campus at a time. Civil Eats. Retrieved from http:/ / civileats.com/2017/02/28/building-a-sustainable-food-system-one-campus-at-atime/

Trudeau, D. (2008) Junior partner or empowered community? The role of nonprofit social service providers amidst state restructuring? Urban Studies, 45(13), 2805-2827.

University of Guelph Student Financial Services. (2017). University of Guelph, Meal Plans. Retrieved from https://www.uoguelph.ca/registrar/studentfinance/fees/mealplans

University of Toronto Food Services. (2017). University of Toronto, Meals Plans. Retrieved from https://ueat.utoronto.ca/purchase-a-meal-plan/

University of Victoria Food Services. (2017). University of Victoria, Meal Plan Options. Retrieved from https://www.uvic.ca/services/food/mealplans/meal-plan-options/index.php

Wakefield, S. (2007). Reflective action in the academy: exploring praxis in critical geography using a "food movement" case study. Antipode, 39(2), 331-354.

Weis, A. (2007). The global food economy: The battle for the future of farming. Halifax: Fernwood.

Winson, A. (2013). The industrial diet: the degradation of food and the struggle for healthy eating. Vancouver: UBC Press.

Wittman, H., Desmarais, A., \& Wiebe, N. (2010). Food sovereignty: reconnecting food, nature and community. Halifax: Fernwood Publishing. 